\title{
Keeping together: older people in longitudinal research studies, the case of TwinsUK
}

\author{
Gill Mein, Taha Bhatti, Sarah Bailey, Claire J. Steves, Deborah Hart, \\ Paz Garcia and Anthea Tinker
}

\begin{abstract}
Purpose - A decline in participation in research studies as people age is inevitable as health declines. This paper aims to address this by collecting data from a group of participants to examine their reasons for declining attendance and suggestions for maintaining attendance as participants age.

Design/methodology/approach - This research used a postal self-completed questionnaire including open and closed questions. The questionnaire was sent to those participants who have declined to attend further clinic visits. Results were analysed using thematic content analysis.

Findings - The study had a 51\% response rate. Participants reported difficulty with travelling to the clinic, and health as the main issues in addition to family demands and a lack of understanding regarding the continuing participation of a singleton twin.
\end{abstract}

Research limitations/implications - This study could only include data from responding participants, answers to open question also included comments from participants regarding their twin.

Practical implications - An anonymous questionnaire was sent to all individuals in the Keeping Together project. It was therefore not possible to identify if responses were from both members of a twin pair.

Originality/value - Maintaining participation in longitudinal studies is of crucial importance to enhance the value of data. Retention of participants in studies may change as people age and health becomes impaired. Suggestions for maintaining and improving the retention of older participants have been identified and are generalisable to other longitudinal studies of ageing.

Keywords Ageing, Older people, Retention, Recruitment, Longitudinal, TwinsUK

Paper type Research paper

\section{Introduction}

Research that follows people over a period of time - longitudinal studies - are increasingly being recognised as of great importance to help understand the ageing process. However, as one study noted "the decline in participation rates is notable and this is particularly significant among older people" (Tinker et al., 2009). If people do drop out (attrition), this can cause the sample to become unrepresentative.

The research we are reporting here is based on the long running study of twins, based at St Thomas' Hospital, London: TwinsUK. It is the UK's largest registry of adult twins. It was started in 1992 and encompasses over 15,000 volunteer male and female twins aged 18-103 from all over the UK (Bowyer et al., 2019; Verdi et al., 2019). It is predominately female $(82 \%)$ and middle-aged people (mean age, 59).

In 2012, more than $70 \%$ of the registered twins filled in at least one detailed health questionnaire and about half of them underwent a baseline comprehensive assessment and
(Information about the authors can be found at the end of this article.)

(C) Gill Mein, Taha Bhatti, Sarah Bailey, Claire J. Steves, Deborah Hart, Paz Garcia and Anthea Tinker. Published by Emerald Publishing Limited. This article is published under the Creative Commons Attribution (CC BY 4.0) licence. Anyone may reproduce, distribute, translate and create derivative works of this article (for both commercial and non-commercial purposes), subject to full attribution to the original publication and authors. The full terms of this licence may be seen at http:// creativecommons.org/licences/ by/4.0/legalcode

Twins UK is funded by the Wellcome Trust [202786/Z/16/ Z], Medical Research Council, European Union, Chronic Disease Research Foundation (CDRF), Zoe Global Ltd and the National Institute for Health Research (NIHR)-funded BioResource, Clinical Research Facility and Biomedical Research Centre based at Guy's and St Thomas' NHS Foundation Trust in partnership with King's College London. 
two follow-up clinical evaluations (Moayyeri et al., 2012). The principal aim of the study is to provide "a multidisciplinary platform for the study of complex disease during the adult lifecourse, including the process of healthy ageing" (Verdi et al.).

Due to the mean age of the cohort and the length of time of participation for some participants, it is anticipated that attrition may become increasingly common in the TwinsUK cohort. This is problematic as TwinsUK has collected much valuable information from these participants over the years, including health measures and genetic sequencing. It is in the interest of good quality health research into ageing to retain participants in TwinsUK and other cohorts for as long as possible. To do this, it is important to understand why participants drop out of studies they have taken part in for many years.

\section{Methodology}

In the TwinsUK study, participants are invited to go to St Thomas' Hospital, London, approximately every four years for research visits comprising mental and physical measurements and tests. Participants who indicated that they were no longer able or willing to attend clinic visits in London were given the opportunity to participate in a new project within TwinsUK named Keeping Together. The aim of Keeping Together is to maintain contact with and accommodate the needs of ageing (aged 60 years and above) twins who are becoming frail by offering them the opportunity to continue to participate in the research from their own homes. This home-based postal study collects important follow-up data and biological samples from these elderly, frail twins through a box delivered by post. TwinsUK sends Keeping Together participants a box which contains health questionnaires and sample collection kits for stool, urine, saliva and blood, which the participants are asked to complete and return.

To understand why these participants had chosen not to continue attending clinical visits, a postal survey was sent out in January 2019 to 151 eligible participants of Keeping Together. In total, 91\% were female and 98\% lived outside London. To enable full responses, the surveys were returned as anonymous. This comprised participants who:

\section{- had agreed to take part in Keeping Together (20);}

- had not been contactable/not yet replied to the invitation to take part; and

- had to those who had declined to take part.

The questionnaire consisted of three sets of questions using Likert scales for responses. The first asked participants to choose a general statement about why they were no longer attending twin visits. The second question asked participants to choose if they agreed or disagreed with more study specific statements for not attending twin visits and the third question asked participants to choose if they were (or were not) influenced by staff at a previous visit. The Likert scales offered five points including strongly disagree, disagree, neither agree or disagree, agree or strongly agree. Participants were then asked using two open questions to give any further reasons for why they no longer attend twin visits and how they thought the study could be changed - to help "Keep Together". A stamped addressed envelope was included for participants to return their results.

\section{Results}

Questionnaires were sent to potential Keeping Together participants who had been unable to attend the previous clinic based twin research visits, where a range of physical and psychological tests are done. Of the 151 participants surveyed, 79 
returned a postal survey giving a response rate of $52 \%$ over a period of five months (January-May 2019). A few participants did not complete the full questionnaire and ticked only one or two boxes per table but wrote comments which accounts for the high amount of the missing data. In total, 69 participants wrote free text comments.

In response to the first set of questions regarding general statements for not attending visits (Figure 1), the majority of participants did not agree the "study took up too much time", but agreed "the journey was too long or difficult"; however, those who answered did not agree "a longstanding illness affected their participation" and did not agree they were "not interested in the study". The other statements did not indicate an overall majority in either direction.

The statement in the second set of questions included more specific statements about reasons for their non-participation (Figure 2) and found most agreement with the statements: "my twin has withdrawn", "the relationship with my twin has changed" and disagreement with the statement "I found the visit too stressful".

\section{Figure 1 Responses to general statements about not attending study visits}

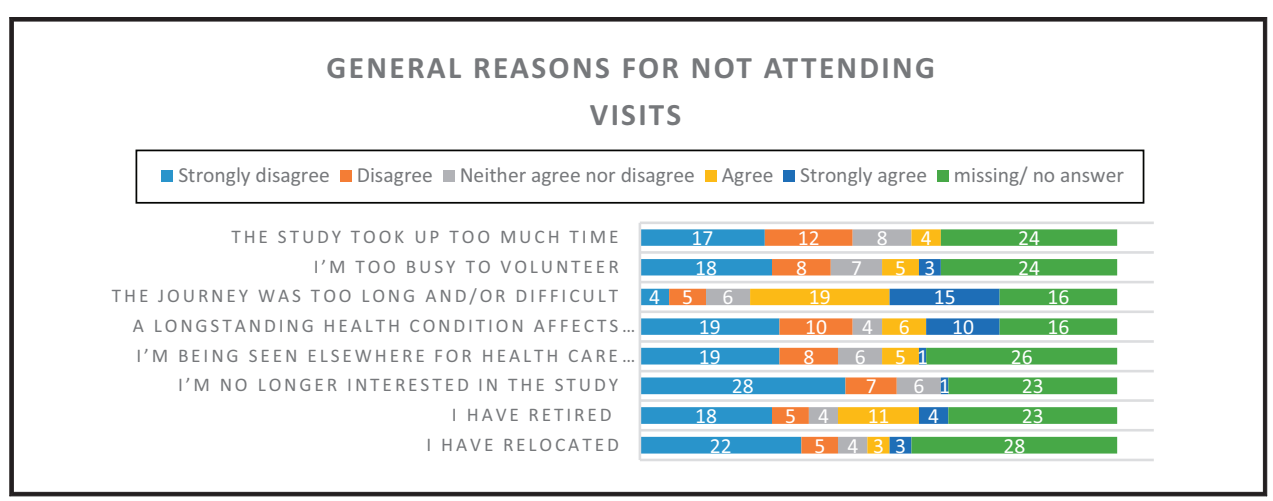

\section{Figure 2 Responses to study specific statements about not attending study visits}

\section{STUDY SPECIFIC REASONS FOR NO LONGER ATTENDING VISITS}

$\square$ Strongly disagree $\square$ Disagree $\square$ Neither agree nor disagree $\square$ Agree $\square$ Strongly agree $\square$ missing/ no answer

I FOUND THE VISIT TOO STRESSFUL

THERE WERE TOO MANY TESTS

I FOUND THE TESTS EMBARRASSING/INTRUSIVE

I HAVE ISSUES OF FAMILY / TWIN PRIVACY E.G.

I FEEL COMPETITION WITH MY TWIN AT THE

MY TWIN HAS WITHDRAWN

MY RELATIONSHIP WITH MY TWIN HAS CHANGED

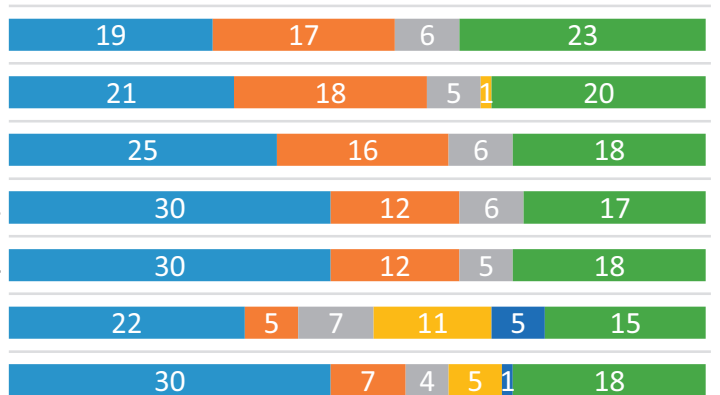


Sixty-seven participants responded to the free text question "We would be very grateful if you could write in any further reasons why you no longer attend twin visits", and thirty-one participants gave a comment in response to "and how do you think we could improve the study to help us Keep Together?"

The answers participants gave varied from a single sentence to several sentences and some, although not all elaborated the options participants chose in the previous closed questions. A coding frame was devised to describe the thematic content of the comments. The free text comments were analysed and given themes, the table below gives the list of themes and indicates the number of times themes were mentioned (Table 1).

The free text comments to the open questions were analysed using thematic content analysis (Green and Thorogood, 2018).

Four main themes from the free text comments emerged, the journey (including costs), health, time limitations (including family commitments) and confusion about the participation of a singleton twin. Suggestions for maintaining participation were also offered. Within these four themes there were subheadings and the themes overlapped. Some answers were given in relation to the participant answering the questionnaire, but some participants reported about their twin as well. The numbers given next to the quotes (below) relate to the individual participant number, assigned according to the order in which the survey responses were logged and read. The results to the Likert scales will be given within these themes.

\section{The journey}

The data collection at clinic visits is done in central London at St Thomas' Hospital. Reasons given regarding the journey related to the participant themselves, but many also reported about their twins' view of the journey:

I am not visiting St Thomas' Hospital because my twin finds the journey too stressful. She lives in

Yorkshire and one visit involves staying with me the night before and after. I personally would still

be attending (17)

Several participants mentioned the length of the journey particularly as they had to travel long distances. For some, the poor journey experience impacted on their health and how they were feeling on the day. A deterioration in health can also affect a person's confidence in travelling.

\section{Table 1 List of themes, and number of times mentioned in the open question request for comments}

Themes

No. of times themes were mentioned

\section{Negative journey}

Participants own health

(other)Twins health

Family commitments

Time restrictions

Expense of visit

Single twin attendance

Positive comments about study

Negative comments about study

Wants to maintain contact

Suggestions for future 
Whenever possible to visit I always found it interesting and a good opportunity to mix and share with other twins. It is really my mobility problems that create my stress and anxiety in visiting London (58)

Since moving I find that connecting buses with trains takes a big part of the day. I thank twin research for taking an interest in me. The times I visited found it very interesting, I would have liked to continue but being nearly 86 my legs are not what they used to be (51)

My Twin will not travel to London (75)

These quotes expanded upon the Likert statement saying the journey was too long and/or difficult.

\section{Costs}

Despite financial support from TwinsUK for travelling, some participants still found it expensive.

It is a long day for us to come to London and at our age we need to stay the night. I know you help with the costs but we live away from the station [...] (40)

Similarly, some participants were still working, and this meant time taken off to attend the clinic cost them earnings or time off work:

I'm now self-employed and paid by clients hourly so time off to participate costs me money (55)

The expense and the effort making the journey appeared to outweigh the benefits for those elderly participants.

Several comments included details about the journey and included participants' reports of struggling, long distances, dislike of travelling in London and the expense of travelling. TwinsUK includes participants from a wide area across the UK, and as people age travelling becomes more of a problem. People have indicated public transport does not meet their needs especially in rural areas (Holley-Moore and Creighton, 2015).

\section{Health}

Health becomes an increasing barrier to participation as people age, and participants mentioned their own health, the health of their twin, and of their family affecting their participation in the visits. In some cases, it was the health of both twins that prevented attendance at a research clinic visit:

My twin and I have mobility issues. I enjoyed the participation but now health issues prevent continuation. They were all very pleasant and helpful. I appreciate the information coming from the studies etc. but having health and mobility issues make it very difficult to make long journeys (30)

Many older people are now taking the role of a carer for family members or spouses, as this man reported:

However the main reason for my retiring from the twin research programme is because my wife has been diagnosed with vascular dementia and most of my time is taken up being her carer (34)

Of course, health problems are not always long term, and some issues are resolved in the short term. Some participants said they were too busy in the long term as in the previous quote and others in the short term as the participant below explained: 
We were looking after our mother who had become ill and subsequently died. We would consider coming in the future (4)

The Likert scale results indicate that some participants have a longstanding illness as the participant below mentioned:

Have never attended twin visits. We are now 73, both have Parkinson's disease, live in Cornwall (57)

\section{Time}

Time was an issue for some participants, and for some, this was in addition to needing to take time off for family responsibilities:

Until recently I was working 5 days a week. In recent years we have had a number of family illnesses and bereavements. I have a mother in law with dementia and I have my own health issues. I felt that my boss although sympathetic was tiring of my need to keep asking for time off for varying reasons [...] (41)

However, very few participants agreed with the general statement about the study taking up too much of their time.

\section{Family commitments}

Family commitments included comments about a participant's spouse, or wider family. The comments included positive and negative comments with the family offering to bring the participant to a twin visit or the family relying on the participant's help and therefore the participant unable to attend the visit.

The reason I am not part of the twins study is mainly my family (daughter and her family) call a lot for my help plus I am not keen on travelling on my own. I hope the twins study is still ongoing and sorry that I have to give it up. I am in good health myself I don't feel my age 78 years (60)

Too far to travel and family commitments (9)

\section{Surviving or singleton twin}

There seemed to be an overall lack of clarity as to whether the study was interested in a single twin attending. Participants commented that their twin could not or would not attend and therefore they themselves would not be attending. The confusion included, if the other twin had died, or was too infirm to travel, or the journey was too far for the other twin to travel:

\footnotetext{
I agree with your study, I can’t do it anymore because my sister died. But keep up with the good work (72)

If you are interested in a surviving twin then my daughter says she will bring me (12)

My twin and I would still very much like to continue with questionnaires but are unable to make visits as I live in London so no problem but my twin lives in Hampshire and is still working (36)
}

My twin brother died in 2010. I have not been invited since. I would be willing to make twin visits (66)

The reader has to accept the comments given on face value, although it is possible that the reasons given are in justification of the respondent no longer participating, even though they 
might be about the other twin. However, clarification needs to be given regarding the value of one twin continuing to participate in the study.

Suggestions for maintaining participation. Participants had suggestions for making the data collection easier for them to attend. Unsurprisingly, all the suggestions for improving participation were about improving access, by making local data collection points, therefore making the travelling distance shorter:

As the numbers of twins increase I feel the study should go out to the people's area and not come to London. Either GPs are involved or mobile units go out (38)

A couple of participants reported they were being seen for health care elsewhere and suggested the study should link up.

Maybe more information via newsletter. Maybe more sessions in the provinces quite a few years ago you held a study at Leeds which both my twin and I found very helpful (58)

Predictably, there were participants who reported not having been sent questionnaires or invitations to clinic visits. One respondent requested clinic visits at the weekend.

\section{Limitations of the research}

This survey was sent out to participants of the "Keeping Together" study, who had indicated they were no longer able or willing to attend clinic visits in London. The recipients of the survey included 21 twin pairs but because the survey was sent out anonymously and to individuals to enable full responses, it was not clear if both of the twin pair had responded.

Some of the questions may have been obscure to answer as it was left open for the participant to state if they were affected by a positive/negative experience. For example: "I am influenced by my experience during a previous visit". However, if twin agreed with the statement regarding previous experience, negative or positive, they were asked to give details. The free text entries combined with the answers shed light on any ambiguities. For example, one participant indicated they themselves had difficulty with language and in the free text the participant explained she had difficulty understanding a member of the screening staff.

\section{Discussion}

Analysis of open questions on a questionnaire can be dismissed as not relevant and not considered as part of a quantitative analysis. However, this is considered unethical as participants have taken time to express their thoughts and opinions which included in free text (O'Cathain and Thomas, 2004).

The response to this survey offered a total of 98 free text comments from participants who had views about not attending centre visits, in addition to the Likert scale questionnaire results.

The largest group of participants in the TwinsUK study are aged between 65 and 74 years. There are fewer participants in younger age groups, indicating as the study continues there will be fewer participants due to deaths of the older participants and the smaller younger cohorts. Therefore, the retention of the existing cohort for as long as possible is of crucial importance.

The main themes of the journey, health, time limitations and involvement of singleton twins were anticipated with an ageing cohort.

Other suggestions included having visits to clinics in local centres or linking up with GP's to collect measures. Home visits are another possibility. In the past, TwinsUK 
implemented a home visit initiative similar to other major longitudinal studies - the Whitehall study (Marmot and Brunner, 2005) and the English Longitudinal Study of Ageing (Steptoe et al., 2013). For TwinsUK a mobile unit comprising a van, driver and clinical staff were sent out to cluster areas populated with registered twins who were unable to visit the clinic. The clinical team and van visited 80 individuals in this mobile home phase from May 2015 to July 2015.

Although popular with participants of TwinsUK, this method proved costly, thus leading to the Keeping Together study where a more cost-effective postal home visit box is used. It is not understood if these methods of contacting participants have contributed to the increase participants withdrawing as they age.

Problems with the journey and health issues might be helped by offering taxis - not just in London but in their home area. If resources permit the whole journey could be by taxi. Not only might this help the participant, but it might make the whole experience a pleasant one. If there are both twins travelling, it might even be more cost effective than complicated individual journeys.

The adoption of technology by older people is a current topic of discussion. The costs of maintaining participation in longitudinal studies is increasing as people become less mobile (Rainsbury, 2019). Peek et al. (2014) concluded that unless older people can see an advantage in adopting any technology they are unlikely to use it. The acceptance of electronic communication and new technology in research while attractive and potentially cost saving will introduce different types of biases, and in longitudinal studies introducing new methods may present advantages and disadvantages. The conference called "Preparing for the future: tackling the key challenges facing the UK's longitudinal population studies (Rainsbury, 2019) acknowledged that whilst the use of new technology may be attractive, longitudinal studies need to carefully consider the biases it introduces and the practical and financial implications they will face. They recommended more research and into what participants are willing to do, and how acceptable they find the use of new technology.

One participant from this study mentioned not being able to using email, but this question was not specifically asked. TwinsUK could investigate how participants would like to be contacted for data collection. There are 1,902 participants aged 75-84 years within the Twins UK and the Office of National Statistics reported that $60 \%$ of people aged over 75 years have either not used the internet in the past three months or had never used the internet in the past three months. In all age groups, those who are less likely to have used the internet in the past few months or who have never used the internet are those who are disabled, or who are economically inactive, live alone and it is important not to exclude these from participating [Office for national Statistics (ONS), 2019]

The value (or not) of a singleton twin attending the study was mentioned repeatedly. The confusion about the value of a single twin was unexpected and the importance of their attendance should be reinforced. However, it is possible that the respondent participant was using the reason their other twin was not attending to support their own reason for not attending.

\section{Conclusions}

It is crucial to maintain participation in longitudinal studies and particularly TwinsUK as a major epidemiological resource with longitudinal genomic and phenomic data collected since 1992. Participants gave health as a key reason for not attending clinic visits, and the health of themselves, their families or their support network. This study 
is unable to influence or indeed improve their health to facilitate continued access to data collections. However, we can consider expediting the points participants suggested for enabling clinic visits for data collection. This study found that participants would appreciate support with travelling to clinic visits either by reducing the journey length, collecting data locally or linking data collection with GPs. This is of importance as participants age, are less mobile and some of these are outlined in a previous study (not of twins) (Tinker et al., 2009; Bhamra et al., 2008).

The importance of singleton twins remaining in the study should be emphasised and supported, together with the issue of travelling alone to the clinic if they have not done this previously.

Future data collections could be improved by having a focus group exploring what participants think could encourage them to continue participating and how they would prefer to have their data collected. Consideration could be given to the cost of funding visits travel and overnight stay.

We offer this article to contribute to the discussion about keeping people, especially older ones, in longitudinal studies and would welcome feedback.

\section{References}

Bhamra, S., Tinker, A., Mein, G., Ashcroft, R. and Askham, J. (2008), "The retention of older people in longitudinal studies: a review of the literature", Quality in Ageing and Older Adults, Vol. 9 No. 4, pp. 27-35, doi: 10.1108/14717794200800025 (accessed 13 February 2020).

Bowyer, R., Jackson, M., Le Roy, C., Lochlain, M., Spector, T., Dowd, J. and Steves, C. (2019), "Socioeconomic status and the gut microbiome: a TwinsUK cohort study", Microorganisms, Vol. 7 No. 1, p. 17, available at: www.mdpi.com/2076-2607/7/1/17 (accessed 13 February 2020).

Green, J. and Thorogood, N. (2018), Qualitative Methods for Health Research, Sage, pp. 258-268.

Holley-Moore, G. and Creighton, H. (2015), "The future of transport in an ageing society", AgeUK, available at: www.somersetintelligence.org.uk/files/Future_of_Transport_in_an_Ageing_Society_Jun2015-AgeUK.pdf (accessed 13 February 2020).

Marmot, M. and Brunner, E. (2005), "Cohort profile: the Whitehall II study", International Journal of Epidemiology, Vol. 34 No. 2, pp. 251-256, available at: https://academic.oup.com/ije/article/34/2/251/ 746997

Moayyeri, A., Hammond, C., Valdes, A. and Spector, T. (2012), "Cohort profile: TwinsUk and healthy ageing twin study", International Journal of Epidemiology, Vol. 42 No. 1, pp. 76-85, available at: https:// academic.oup.com/ije/article/42/1/76/694046 (accessed 13 February 2020).

O'Cathain, A. and Thomas, K. (2004), "'Any other comments?' Open questions on questionnaires - a bane or a bonus to research?", BMC Medical Research Methodology, Vol. 4 No. 1, p. 25, available at: https://bmcmedresmethodol.biomedcentral.com/articles/10.1186/1471-2288-4-25 (accessed 13 February 2020).

Office for national Statistics (ONS) (2019), "Internet users", available at: www.ons.gov.uk/businessindustry andtrade/itandinternetindustry/bulletins/internetusers/2019 (accessed 13 February 2020).

Peek, S.T., Wouters, E.J., van Hoof, J., Luijkx, K.G., Boeije, H.R. and Vrijhoef, H.J. (2014), "Factors influencing acceptance of technology for aging in place: a systematic review", International Journal of Medical Informatics, Vol. 83 No. 4, pp. 235-248, available at: www.ncbi.nlm.nih.gov/pubmed/24529817 (accessed 13 February 2020).

Rainsbury, M. (2019), Conference proceedings: Preparing for the future: Tackling the key challenges facing the UK's longitudinal population studies, CLOSER, the home of longitudinal research, available at: www. closer.ac.uk/wp-content/uploads/20190401-Preparing-for-the-future-Conference-report.pdf (accessed 13 February 2020).

Steptoe, A., Breeze, E., Banks, J. and Nazroo, J. (2013), "Cohort profile: the English longitudinal study of ageing", International Journal of Epidemiology, Vol. 42 No. 6, pp. 1640-1648, available at: www.ncbi.nlm. nih.gov/pubmed/23143611 (accessed 13 February 2020). 
Tinker, A., Mein, G., Bhamra, S., Ashcroft, R. and Seale, C. (2009), "Retaining older participants in health research studies: some ethical issues", Research Ethics Review, Vol. 5 No. 2, pp. 71-74, available at: https://journals.sagepub.com/doi/abs/10.1177/174701610900500206 (accessed 13 February 2020).

Verdi, S., Abbasian, G., Bowyer, R., Lachance, G., Yarand, D., Christofidou, P., Mangino, M., Menni, C., Bell, J., Falchi, M., Small, K., Williams, F., Hammond, C., Hart, D., Spector, T. and Steves, C. (2019), "TwinsUK: the UK adult twins registry update", Twin Research and Human Genetics, Vol. 22 No. 6, doi: 10.1017/thg.2019.65 (accessed 13 February 2020).

\section{Author affiliations}

Gill Mein is based at the Faculty of Health, Social Care and Education, Kingston University and St George's University of London, London, UK.

Taha Bhatti, Sarah Bailey and Claire J. Steves are all based at the Department of Twin Research, King's College London, London, UK.

Deborah Hart and Paz Garcia are both based at the Department of Twin Research and Genetic Epidemiology, King's College London, London, UK.

Anthea Tinker is based at the Department of Global Health and Social Medicine, Institute of Gerontology, King's College London, London, UK.

\section{Corresponding author}

Gill Mein can be contacted at: g.mein@sgul.kingston.ac.uk

For instructions on how to order reprints of this article, please visit our website: www.emeraldgrouppublishing.com/licensing/reprints.htm

Or contact us for further details: permissions@emeraldinsight.com 